Original Paper

\title{
Effect of Triangular Fins on Critical Heat Flux in Ethanol-cooled Combustion Chamber
}

\author{
By Masao TAKEgoshi ${ }^{1)}$, Ryosuke SUZUKI ${ }^{2}$, Toshihito SAIto $^{1)}$, Fumiei ONO ${ }^{1)}$, Tetsuo HIRAIWA ${ }^{1)}$ and Sadatake TomiokA ${ }^{1)}$ \\ 1) Japan Aerospace Exploration Agency, Kakuda, Japan \\ ${ }^{2)}$ Tohoku University, Sendai, Japan
}

(Received June 27th, 2011)

\begin{abstract}
A pressure-fed engine with a regeneratively-cooled combustion chamber is studied in JAXA. Operation chamber pressure is approximately $1 \mathrm{MPa}$. A proposed propellant combination is liquid oxygen and ethanol. However, it is necessary to understand the critical heat flux when ethanol is used as a coolant for regeneratively-cooled combustion chamber because the saturation pressure of it is $6.3 \mathrm{MPa}$. In general, it is known that the cooling wall with fins improves the cooling performance. In this study, the effect of triangular fins on critical heat flux of ethanol in ethanol-cooled combustion chamber was investigated. As the result, it was found that the critical heat flux of cooling wall with triangular fins was $23 \%$ higher than that of that without fin in the same velocity condition of the coolant. The critical heat flux increases by the triangular fins on the cooling surface due to the effect of the combination cooling with film boiling and nucleate boiling.
\end{abstract}

Key Words: Ethanol, Critical Heat Flux, Triangular Fin, Regenerative Cooling, Nucleate Boiling

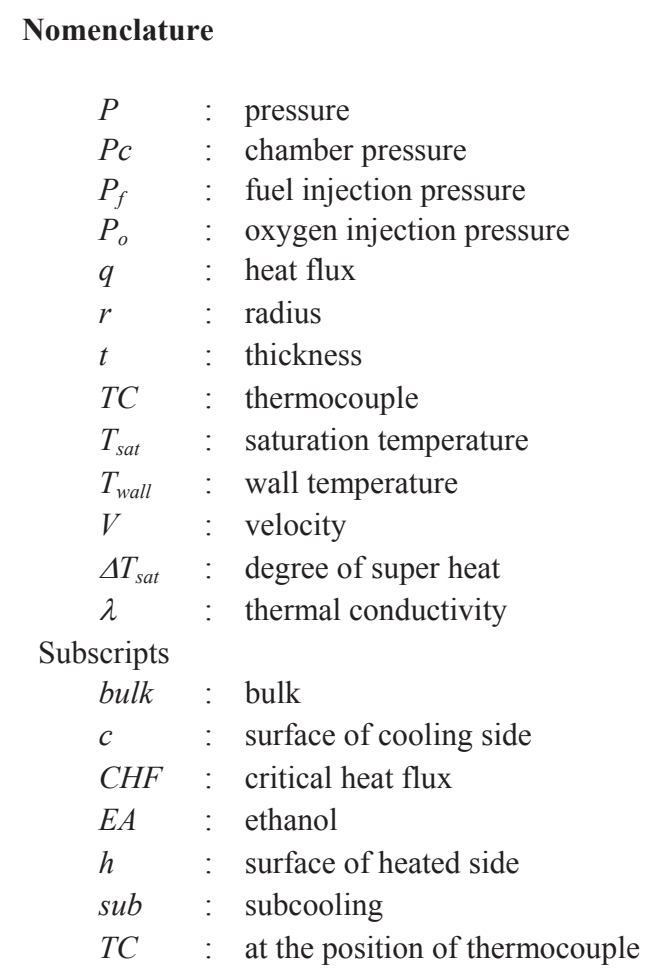

\section{Introduction}

Experimental research work for the ethanol propulsion system has been performed in JAXA/Space Transportation Mission Directorate as study for future reusable launch vehicle. LOX/ethanol rocket engine is thought to be one of the promising candidates to realize a next generation's reusable launch vehicle with low cost and high frequency. Fujii and
Ishimoto discussed to develop a small rocket-powered winged vehicle that will be launched from a platform aircraft and has also conducted a concept study of such a flight demonstrator ${ }^{1)}$. Because the ethanol is nontoxic, liquid at the room temperature, and easy to handle as a fuel ${ }^{2}$, rocket engines using LOX and ethanol seemed to be the most suitable for this reusable experimental vehicle. JAXA has started the development of technologies necessary to realize the reference systems ${ }^{1)}$. A pressure-fed engine with a regeneratively-cooled rocket combustion chamber ${ }^{3)}$ was started to study in 2009. Operation chamber pressure is approximately $1 \mathrm{MPa}$. However, it is necessary to understand the critical heat flux when it is used as a coolant for regeneratively-cooled combustion chamber because the saturation pressure of it is $6.3 \mathrm{MPa}$.

Previous studies ${ }^{4,5)}$ of critical heat flux for fluids at subcooling conditions have been conducted using electrically heated tubes, and they indicated that the cooling performance of ethanol was not enough for regeneratively-cooled combustion chamber. On the other hand, Niino et al. ${ }^{6)}$ reported that the critical heat flux was increased by the cooling wall with triangular fins of water-cooled chamber.

In this study, the effect of triangular fins on critical heat flux of ethanol in ethanol-cooled combustion chamber was investigated experimentally.

\section{Experimental Procedure and Experimental Apparatus}

\subsection{Test facility and test apparatus}

Figure 1 shows the simplified schematic of the test facility to measure the critical heat flux of ethanol under sub-cooling conditions. Combustion gas generated by gaseous hydrogen and gaseous oxygen was used as a heat source. The combustion chamber consisted of three water-cooled 
chambers and an ethanol-cooled chamber. Figure 2(a) shows the schematic of the test chamber. The lengths of water-cooled chambers were $100 \mathrm{~mm}$ and $142 \mathrm{~mm}$ for cylinder parts, and $70 \mathrm{~mm}$ for the nozzle throat, respectively. The length of the ethanol-cooled cylinder chamber was $20 \mathrm{~mm}$. The combustion

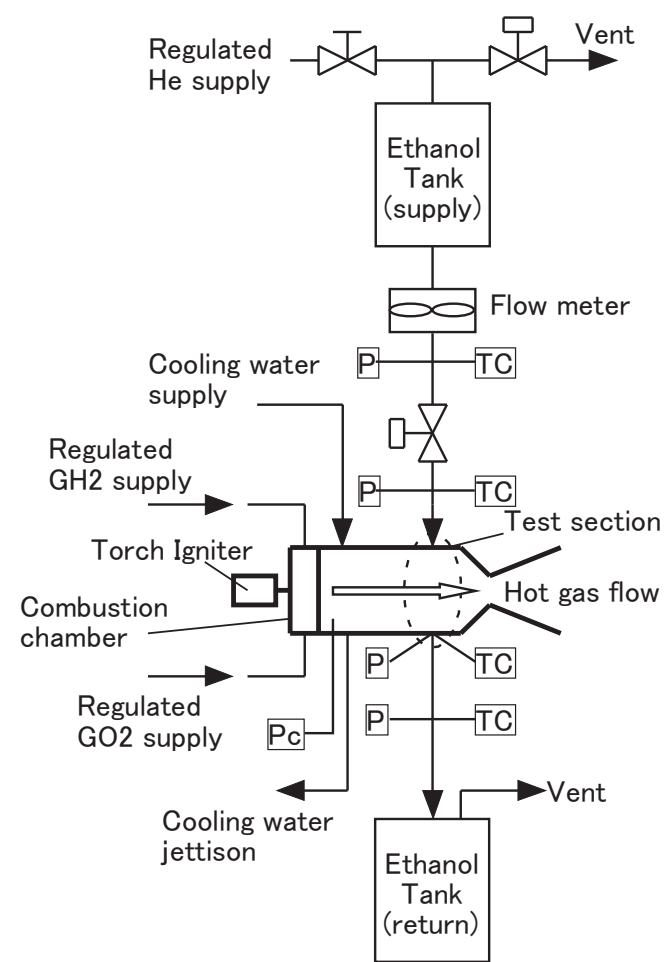

Fig. 1. Simplified schematic of the test stand for evaluation of the cooling performance. chamber is $50 \mathrm{~mm}$ in diameter. The throat is $26 \mathrm{~mm}$ in diameter.

Eight co-axial injectors, each with an oxygen post and a hole in the faceplate, were installed at equal distance around the torch igniter. The inner path of the co-axial injector was for gaseous oxygen and outer path was for gaseous hydrogen. The oxygen injector posts and faceplate were made of nickel. The faceplate had twenty-four cooling fuel injection holes, each being $0.5 \mathrm{~mm}$ in diameter.

Two kinds of cooling passage were used for ethanol-cooled combustion chambers. One is the cooling surface with triangular fins. Another is the cooling surface with flat surface. Figure 2(b) shows the contour of the cooling passage in detail. The height of each fin is $1.5 \mathrm{~mm}$. The coolant flows in the direction of the circumference of the chamber. The width of the cooling passage is $10 \mathrm{~mm}$ in width and $3 \mathrm{~mm}$ in height. The thickness of the chamber wall was $4 \mathrm{~mm}$. The wall temperature at the $2 \mathrm{~mm}$ from the surface and the bulk temperature of coolant ethanol was measured by thermocouple at the position of $3 / 8$ rounds away from the inlet. The pressure of coolant ethanol was also measured with pressure transducers at the position of $3 / 8$ rounds away from the inlet.

\subsection{Procedure and test sequence}

In the electrically heated tube tests, the method that the heating power was increased in steps until the heat flux approached a critical heat flux while keeping the flow rate and pressure of coolant stable was used. In this study, the flow rate of ethanol at the critical heat flux was measured by decreasing the pressure of ethanol supply tank while keeping the chamber pressure stable.

Figure 3 shows a typical test sequence of heating test. A typical test run started by filling the supply tank with

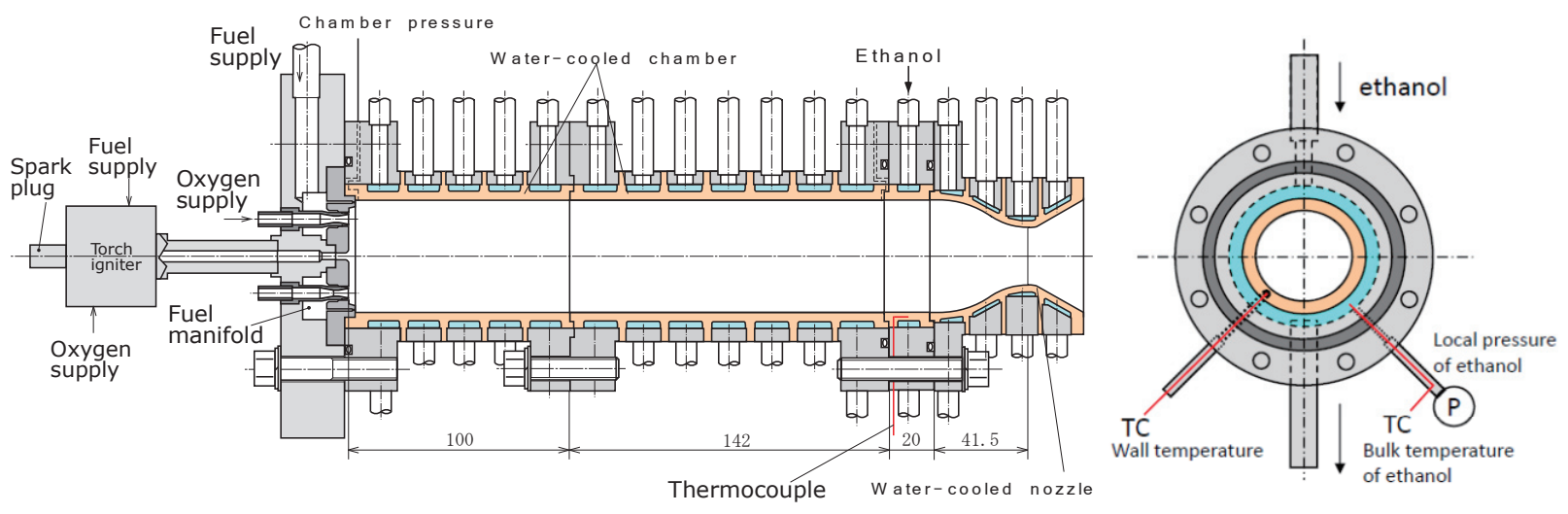

(a) water-cooled chambers and an ethanol-cooled chamber

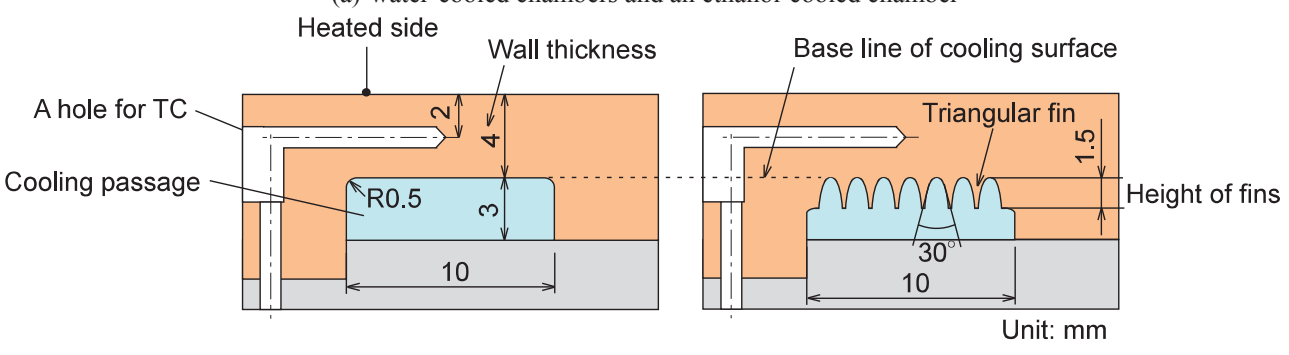

(b) cooling passage with flat surface and with fins

Fig. 2. Schematic of heating apparatus. 


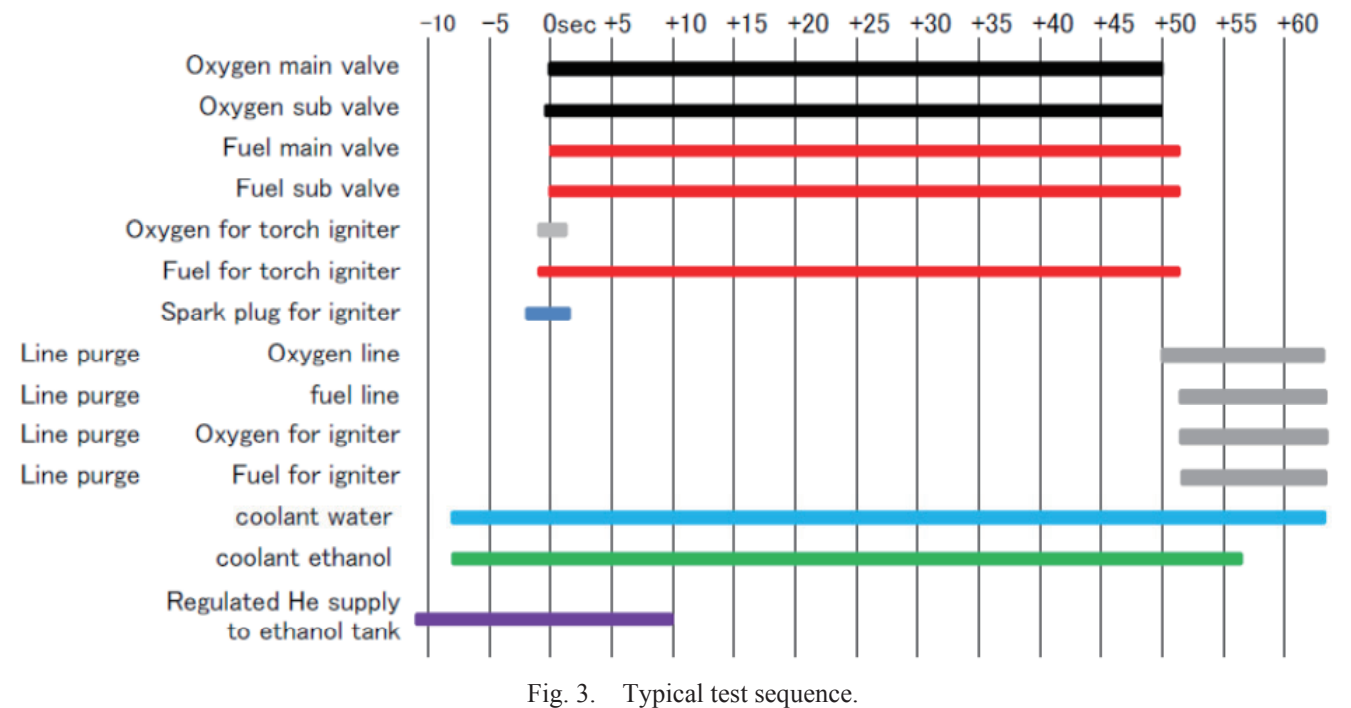

regulated helium gas. First, the shut-off valve for coolant was opened $8.0 \mathrm{~s}$ prior to ignition. The coolant flow was stabilized at flow rate and back pressure set points prior to firing. A torch spark plug was operated $1.0 \mathrm{~s}$ prior to $\mathrm{GH}_{2}$ and $\mathrm{GO}_{2}$ injections into the igniter. Though the oxygen supply to the igniter was cut off $1.5 \mathrm{~s}$ after the onset of the main injection, the hydrogen supply to the igniter was continued to cool the injector faceplate.

After stabilization of chamber pressure, the supply valve to the ethanol tank was closed at $10.0 \mathrm{~s}$. As the pressure of ethanol tank decreased automatically, the flow rate of coolant was decreased gradually. When the critical heat flux was reached, the wall temperature at the thermocouple showed a sharp increase. The sharp increase in wall temperature indicated the drastic reduction in heat transfer coefficient of the fluid as it transitioned to film boiling. When the wall temperature exceeded $550 \mathrm{~K}$, heating test was stopped automatically.

Heat flux was calculated based on the temperature difference between inlet and outlet, the specific heat, flow rate, density of the coolant fluid. Coolant side wall temperature was calculated based on the heat flux, conductivity of wall material, and wall temperature measured by thermocouple. The heat flux to the wall was controlled by combustion pressure. Combustion pressure was kept at constant during each test.

The pressure of coolant in the cooling passage was assumed to be from 1.4 to $1.6 \mathrm{MPa}$ because the maximum pressure of a fuel tank of the flight demonstrator ${ }^{1)}$ was $2.0 \mathrm{MPa}$. The range of the pressure condition was set from 0.8 to $2.0 \mathrm{MPa}$ to investigate the effect of coolant pressure on critical heat flux.

\subsection{Measurement}

Measurement was conducted using personal computer (Dell Optiplex960) with a data acquisition board (DAQ) and SCXI series of National Instruments Corporation. A measurement software Labview was used. The measuring instruments were put on a special box to which the dry nitrogen gas was continuously sent. The heating test was started more than 30 minutes after the temperature of hardware was steady.

During tests, combustion chamber pressure $(\mathrm{Pc})$, fuel injection pressure $\left(\mathrm{P}_{\mathrm{f}}\right)$, oxygen injection pressure $\left(\mathrm{P}_{\mathrm{o}}\right)$ and coolant pressure $(\mathrm{P})$ were measured with strain-gage pressure transducers (PG-U series, KYOWA ELECTRONIC INSTRUMENTS CO., LTD.). All pressure transducer was calibrated with pressure calibrator (Dead weight tester, PD27 of Nagano Keiki CO., Ltd) before the tests. A sensor for 5 $\mathrm{MPa}$ was used for Pc pressure measurement and coolant pressure measurement; measurement error was $\pm 0.01 \mathrm{MPa}$. A sensor for $10 \mathrm{MPa}$ was used for $\mathrm{P}_{\mathrm{f}}$ and $\mathrm{P}_{\mathrm{o}}$ pressure measurement, measurement error being $\pm 0.02 \mathrm{MPa}$.

The test stand had turbine-type flowmeters to measure the flow rates of fuel, oxygen and ethanol directly, their measurement error being $\pm 1 \%$ in volume flow rate. Pressure and temperature within the supply lines close to the flowmeters were monitored to deduce mass flow rate. The temperatures of coolants were measured by thermocouples of type E (chromel-constantan thermocouple). The electronic cold junction compensation of acquisition device of National Instruments Corporation was used for the temperature compensating.

The temperature of the chamber wall at $2 \mathrm{~mm}$ from the surface was measured by thermocouples, as shown in Fig. 2. The points measured by thermocouples are indicated as TC. The wall temperature was measured by thermocouple of type $\mathrm{K}$ (chromel-alumel thermocouple).

The heat flux distribution to the water-cooled chamber was calculated based on the temperature and flow rate of the coolant. The rocket chamber has sixteen circumferencial water cooling channels. The temperature and pressure of the coolant water were measured at the entrance manifold and the exit of the each cooling channel with thermocouples of type $\mathrm{E}$ and pressure transducers, respectively. The mass flow rate was calculated based on the pressure difference of orifice plate. We measured the correlation between the mass flow rate of the coolant and the difference of the pressure beforehand. 


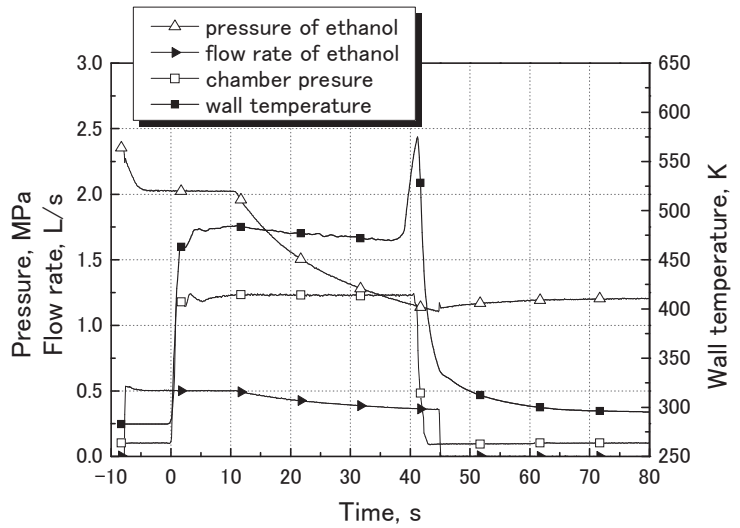

Fig. 4. Time histories of combustion chamber pressure, coolant pressure, wall temperature, and flow rate obtained using the ethanol-cooled chamber without fin in the cooling passage.

\subsection{Coolant properties}

The ethanol for coolant was bought from AMAKASU Chemical Industries. The purity of ethanol was $99 \mathrm{Vol} \%$ or more.

\section{Results and Discussion}

\subsection{Effect of flow rate and pressure of coolant ethanol on wall temperature}

Figure 4 shows the time histories of the chamber pressure, the coolant pressure, the wall temperature, and the flow rate obtained in the case of using the ethanol-cooled chamber without fin in the cooling passage as an example.

The wall temperature of the cooling surface $T_{\text {wall,c }}$ was calculated by the following Eq. (1). At 10 seconds from ignition, $T_{\text {wall,c }}$ was $461 \mathrm{~K}$.

$$
T_{\text {wall }, c}=T_{\text {wall }, T C}-\frac{q r_{h} \ln \left(r_{c} / r_{T C}\right)}{\lambda}
$$

Here, $390 \mathrm{~W} / \mathrm{m} / \mathrm{K}$ was used as the conductivity $\lambda$ of copper, the value of heat flux $q$ was $5.02 \mathrm{MW} / \mathrm{m}^{2}$ at the test, heated side chamber radius $r_{h}$ was $25 \mathrm{~mm}$, cooling side chamber radius $r_{c}$ was $29 \mathrm{~mm}$, the radius at the position of thermocouple $r_{T C}$ was $27 \mathrm{~mm}$. The saturation temperature of ethanol at $2.0 \mathrm{MPa}$ was approximately $457 \mathrm{~K}$. Therefore the nucleate boiling had occurred on the cooling side because the temperature of cooling side was higher than that of the saturation temperature of ethanol. If the forced convection heat transfer had occurred on the cooling side, the wall temperature rose by the decrease of flow rate of ethanol. However, the wall temperature fell though the flow rate was decreased by the decrease of the pressure of ethanol. The reason why the wall temperature fell as flow rate decreased is that the saturation temperature of ethanol that depends on the pressure of the ethanol decreased. After 38 seconds from ignition, the wall temperature increased sharply because of the transition from nucleate boiling to film boiling.

Figure 5 shows the time histories of the chamber pressure, the coolant pressure, the wall temperature, and the flow rate obtained in the case of using the ethanol-cooled chamber with

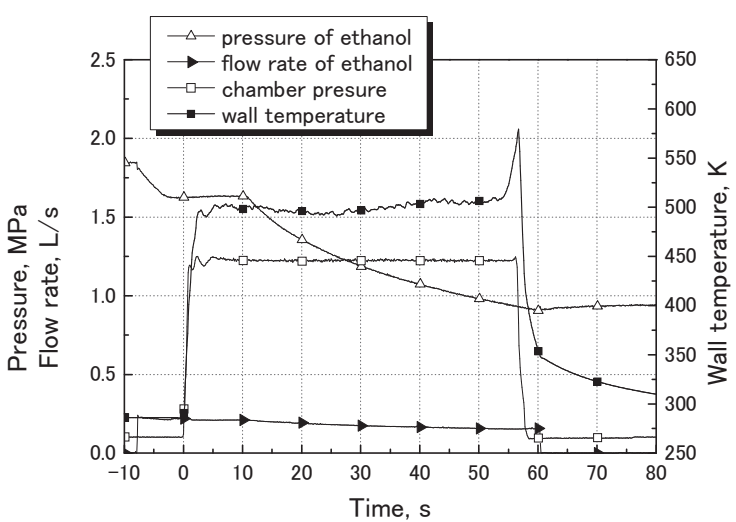

Fig. 5. Time histories of chamber pressure, coolant pressure, wall temperature and flow rate obtained using the ethanol-cooled chamber with fins in the cooling passage.

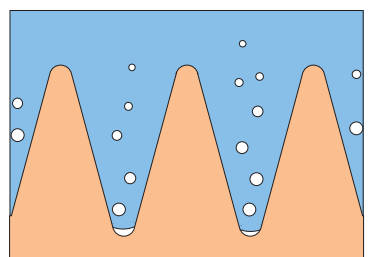

(a)

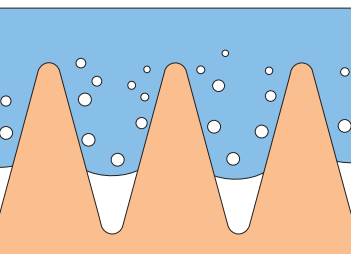

(b)
Fig. 6. cooling conditions

(a) cooling in nucleate boiling condition or combination cooling with forced convection and nucleate boiling

(b) combination cooling with nucleate boiling and film boiling

fins in the cooling passage as an example. After 10 seconds from ignition, the flow rate was decreased by the decrease of the pressure of ethanol. The wall temperature was also decreased by the decrease of the pressure of ethanol. This phenomenon indicated that nucleate boiling had occurred on the cooling side as shown in Fig. 6 (a). After 25 seconds from ignition, the wall temperature increased gradually by $15 \mathrm{~K}$. It was thought that the phenomenon indicated that film boiling had started partially on the cooling side as shown in Fig. 6 (b). After the stable condition of temperature was kept by 53 seconds, the wall temperature increased sharply because the transition from the nucleate boiling to the film boiling occurred at the whole surface area. In the case of the cooling passage with fins, the result of two stage increment of wall temperature was obtained at all the tests.

\subsection{Effect of flow rate of coolant ethanol and triangular fins on critical heat flux}

The test results of the pressure of ethanol, the flow velocity, the critical heat flux, and the heat flux departure from nucleate boiling were summarized in table 1 . The heat flux at the time when the wall temperature measured by thermocouple increased sharply was defined as a critical heat flux in this study. The heat flux at the time when the wall temperature began to increase was defined as a heat flux departure from nucleate boiling. The data of the critical heat flux could not be acquired in two test numbers due to the limited testing time.

Figure 7 shows the effect of the flow velocity of ethanol 
Table 1. Summary of test conditions and results.

\begin{tabular}{|c|c|c|c|c|c|c|c|c|}
\hline Test No. & $\begin{array}{l}\text { Height } \\
\text { of fin } \\
{[\mathrm{mm}]}\end{array}$ & $\begin{array}{l}\text { Local flow } \\
\text { velocity of } \\
\text { ethanol } \\
{[\mathrm{m} / \mathrm{s}]}\end{array}$ & $\begin{array}{l}\text { Critical heat flux* } \\
\text { or heat flux } \\
\text { departure from } \\
\text { nucleate boiling** } \\
{\left[\mathrm{MW} / \mathrm{m}^{2}\right]}\end{array}$ & $\begin{array}{l}\text { Pressure of } \\
\text { ethanol } \\
{[\mathrm{MPa}]}\end{array}$ & $\begin{array}{l}\text { Local } \\
\text { saturated } \\
\text { temperature } \\
\text { of ethanol }[\mathrm{K}]\end{array}$ & $\begin{array}{l}\text { wall temperature } \\
\text { at the position of } \\
\text { thermocouple }[\mathrm{K}]\end{array}$ & $\begin{array}{l}\text { Bulk temperature of } \\
\text { ethanol at the } \\
\text { measurement point } \\
\text { of wall temperature } \\
{[\mathrm{K}]}\end{array}$ & $\begin{array}{l}\text { Chamber } \\
\text { pressure, } \\
\text { Pc [MPa] }\end{array}$ \\
\hline 001 & 0 & 6.37 & 5.34 & 0.79 & 416.3 & 471.7 & 294.6 & 1.34 \\
\hline 002 & 0 & 11.03 & 7.30 & 1.35 & 436.8 & 508.1 & 291.8 & 1.93 \\
\hline 003 & 0 & 10.07 & 6.64 & 1.33 & 436.0 & 499.6 & 290.8 & 1.75 \\
\hline 004 & 0 & 6.00 & 5.02 & 0.90 & 421.2 & 469.7 & 294.1 & 1.34 \\
\hline 005 & 0 & 6.10 & 5.34 & 1.12 & 429.0 & 481.8 & 294.4 & 1.23 \\
\hline 006 & 0 & 4.61 & 4.92 & 0.93 & 422.3 & 471.3 & 294.8 & 1.25 \\
\hline 007 & 0 & 5.41 & 5.34 & 1.37 & 437.3 & 487.7 & 294.5 & 1.34 \\
\hline 008 & 0 & 7.07 & 5.91 & 2.01 & 456.7 & 506.6 & 293.9 & 1.50 \\
\hline 009 & 0 & 7.60 & 5.91 & 1.83 & 452.2 & 504.3 & 293.6 & 1.50 \\
\hline 010 & 0 & 2.72 & 4.00 & 1.06 & 426.6 & 464.6 & 302.0 & 1.03 \\
\hline 011 & 0 & 8.08 & 6.05 & 1.20 & 431.8 & 489.0 & 300.7 & 1.63 \\
\hline $101-1^{\dagger}$ & 1.5 & 4.83 & $5.93 * *$ & 1.65 & 446.4 & 523.0 & 291.9 & 1.46 \\
\hline $101-2^{\dagger \dagger}$ & 1.5 & 4.52 & $5.86^{*}$ & 1.48 & 441.1 & 539.4 & 292.6 & 1.46 \\
\hline $102-1^{\dagger}$ & 1.5 & 7.98 & $6.90 * *$ & 1.25 & 433.5 & 529.5 & 292.6 & 1.82 \\
\hline $103-1^{\dagger}$ & 1.5 & 3.99 & $4.97 * *$ & 1.14 & 430.0 & 493.6 & 296.4 & 1.22 \\
\hline $103-2^{\dagger \dagger}$ & 1.5 & 3.47 & $4.99 *$ & 0.88 & 420.2 & 507.9 & 299.2 & 1.22 \\
\hline $104-1^{\dagger}$ & 1.5 & 4.88 & $5.42 * *$ & 1.12 & 429.3 & 501.3 & 290.3 & 1.35 \\
\hline $105-1^{\dagger}$ & 1.5 & 6.28 & $6.43 * *$ & 1.42 & 439.1 & 525.5 & 290.4 & 1.66 \\
\hline $105-2^{\dagger \dagger}$ & 1.5 & 5.73 & $6.50 *$ & 1.18 & 431.2 & 536.9 & 291.4 & 1.65 \\
\hline $106-1^{\dagger}$ & 1.5 & 2.57 & $4.67 * *$ & 1.41 & 438.7 & 493.4 & 305.6 & 1.12 \\
\hline $106-2^{\dagger \dagger}$ & 1.5 & 2.33 & $4.69 *$ & 1.14 & 429.8 & 494.6 & 305.6 & 1.13 \\
\hline $107-1^{\dagger}$ & 1.5 & 4.97 & $6.17 * *$ & 1.43 & 439.3 & 520.0 & 294.9 & 1.50 \\
\hline $107-2^{\dagger \dagger}$ & 1.5 & 4.46 & $6.15^{*}$ & 1.18 & 431.3 & 529.6 & 295.9 & 1.50 \\
\hline
\end{tabular}

'test number -1: the data at the heat flux departure from nucleate boiling

${ }^{\dagger}$ test number-2: the data at the critical heat flux

and the effect of the triangular fins on critical heat flux for ethanol. The critical heat flux was increased when the flow velocity of ethanol was increased. The critical heat flux of cooling wall with triangular fins was approximately $23 \%$ higher than that of that without fins. Moreover, it was found that the effect of the flow velocity on the critical heat flux did not depend on the ethanol pressure in the range of the ethanol pressure from 0.8 to $2.0 \mathrm{MPa}$. It was observed in Fig. 7 that the critical heat flux is expected to be $12 \mathrm{MW} / \mathrm{m}^{2}$ by extrapolation if the velocity of coolant ethanol reaches $30 \mathrm{~m} / \mathrm{s}$.

\subsection{Effect of triangular fins on wall temperature under} nucleate boiling heat transfer conditions

The difference between the wall temperature of cooling side and local saturated temperature of ethanol is defined as $\Delta \mathrm{T}_{\text {sat }}$. $\Delta \mathrm{T}_{\text {sat }}$ is a degree of super heat and is expressed by Eq. (2).

$$
\Delta T_{\text {sat }}=T_{\text {wall }, c}-T_{\text {sat }}
$$

Figure 8 shows the relationship between $\Delta \mathrm{T}_{\text {sat }}$ and the critical heat flux. The wall temperature of the cooling surface $\mathrm{T}_{\text {wall,c }}$ was calculated by Eq. (1).

In case of the cooling passage with fins, $\Delta \mathrm{T}_{\text {sat }}$ was defined as the difference between the wall temperature at the baseline shown in Fig. 2 and the local saturation temperature of ethanol because the temperature distribution on the cooled surface is not uniform.

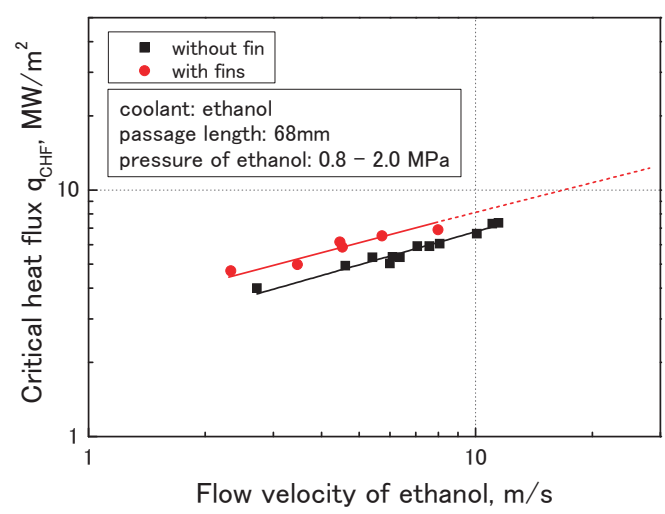

Fig. 7. Effect of flow velocity of ethanol on critical heat flux.

Figure 8 shows that the $\Delta \mathrm{T}_{\text {sat }}$ of cooling passage with fins was higher than that of that without fins. This reason is that the wall temperature of cooling surface was defined as the temperature at the baseline shown in Fig. 2 (b).

However, high value of $\Delta \mathrm{T}_{\text {sat }}$ means the wall temperature being high though the effect of the increment of the critical heat flux by fins can be expected.

Figure 9 shows the calculated wall temperature at heated side surface in case of the cooling passage with fins and 
without fin. The wall temperature was calculated by Eq. (3).

$$
\begin{aligned}
T_{\text {wall }, h} & =T_{\text {wall }, c}+\frac{q r_{h} \ln \left(r_{c} / r_{h}\right)}{\lambda} \\
& =T_{\text {sat }}+\Delta T_{\text {sat }}+\frac{q r_{h} \ln \left(r_{c} / r_{h}\right)}{\lambda}
\end{aligned}
$$

The wall temperature was calculated under the conditions of the wall thickness $\mathrm{t}$ from 2 to $4 \mathrm{~mm}$, the heat flux q from 8 to $15 \mathrm{MW} / \mathrm{m}^{2}$ and the pressure of $1.4 \mathrm{MPa}$. The value of $\Delta \mathrm{T}_{\text {sat }}$ was determined by extrapolation based on Fig. 8 .

The result indicated that the wall temperature was high enough to weaken the wall material strength in case of the cooling surface with fins. However, the surface temperature was below $800 \mathrm{~K}$ that is the temperature expected to keep the strength of wall materials under the condition of heat flux of $12 \mathrm{MW} / \mathrm{m}^{2}$ when the wall thickness is $4 \mathrm{~mm}$.

If flow velocity of coolant ethanol reaches $30 \mathrm{~m} / \mathrm{s}$, it can be presumed that the critical heat flux is $12 \mathrm{MW} / \mathrm{m}^{2}$ in case of cooling surface with fins as shown in Fig. 7. However, it is difficult to achieve the flow velocity of $30 \mathrm{~m} / \mathrm{s}$ because it is necessary to increase the supply pressure of ethanol. It is thought that the upper limitation of heat load to the ethanol-cooled chamber is determined by the limitation of the flow velocity of ethanol, not by limitation of the wall temperature.

\section{Conclusions}

The effect of the triangular fins on critical heat flux was investigated in the ethanol-cooled cylinder chamber using combustion gases as a heat source under the conditions of the pressure of ethanol from 0.7 to $2.0 \mathrm{MPa}$ and the flow velocity from 2 to $12 \mathrm{~m} / \mathrm{s}$. The following conclusions were obtained:

1. The critical heat flux for ethanol at cooling wall with triangular fins of $1.5 \mathrm{~mm}$ in height was approximately $23 \%$ higher than that of that without fin.

2. The wall temperature in case of the cooling passage with fins was higher than that in case of that without fin under the same heat flux condition.

\section{References}

1) Fujii, K. and Ishimoto, S.: Research Activities to Realize Advanced Space Transportation system, AIAA-2009-7275.

2) Tokudome, S., Yagishita, T., Habu, H., Shimada, T. and Daimo, Y.: Experimental Study of an $\mathrm{N}_{2} \mathrm{O}$ /Ethanol Propulsion System, AIAA-2007-5464.

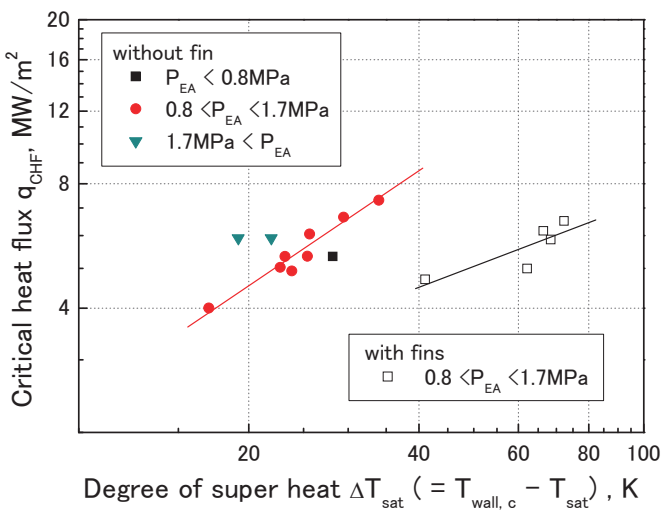

Fig. 8. Relationship between the degree of super heat $\Delta \mathrm{T}_{\text {sat }}$ and the critical heat flux $\mathrm{q}_{\mathrm{CHF}}$.

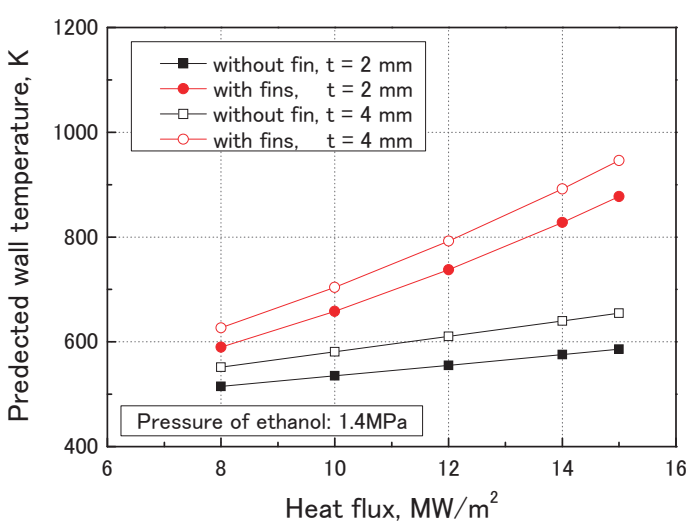

Fig. 9. Effect of heat flux on heated side wall temperature in ethanol cooling.

3) Hiraiwa, T., Saito, T., Tomita, T., Azuma, N., Okita, K., Obase, K. and Kaneko, T.: Research Works of Ethanol Propulsion System for the Future Rocket-plane Experimental Vehicle, AIAA-2011-6114.

4) Meyer, L. M., Linne, L. D. and Rousar, C. D.: Forced convection boiling and critical heat flux of ethanol in electrically heated tube tests, AIAA-98-1055.

5) Greisen, A. D. and Rousar, C. D.: Critical heat flux limits for high velocity, high subcooling water flows, AIAA-97-2912.

6) Niino, M., Kumakawa, A., Yatsuyanagi, N., Gomi, H., Suzuki, A., Sakamoto, H., Sasaki, M. and Yanagawa, K.: A study on Heat Transfer Characteristics of Water Cooled $\mathrm{LO}_{2} / \mathrm{LH}_{2}$ Rocket Combustor, Technical Report of National Aerospace Laboratory, TR-708. 